\title{
Creativity and creative work in children with disabilities
}

\author{
Tamara Gennadievna Bogdanova ${ }^{1 *}$, Elena Nikolaevna Morgacheva ${ }^{2}$, Tatiana Mikhailovna \\ Popova $^{3}$, Olga Yurievna Sokolova ${ }^{2}$, and Nadia Shamilevna Tjurina ${ }^{2}$ \\ ${ }^{1}$ Moscow City University, Institute of Special Education and Psychology, Department of Special \\ Psychology and Psychological and Social Technologies, Moscow, Russia \\ ${ }^{2}$ Moscow City University, Institute of Special Education and Psychology, Department of Special \\ Pedagogy and Complex Reabilitation, Moscow, Russia \\ ${ }^{3}$ Institute of Special Education of the Russian Academy of Education, Department of Further \\ Education and Improvement of Professional Competencies, Moscow, Russia
}

\begin{abstract}
The article presents the results of the analysis of the problem of creativity and creative work in children with disabilities having different impairments. This research serves as a basis for conducting a separate study aimed at researching the peculiarities of the search for creative solutions in the process of completing figure drawings in younger schoolchildren with hearing impairments compared to their peers with normal hearing. For this purpose, a comparative analysis of the drawings of hearing-impaired students and elementary school students with preserved hearing was conducted by the criteria of fluency, flexibility, elaborateness, and originality. The need for the present study is determined by the tasks of the modern system of special and inclusive education aimed at the optimal personal development of all children and the creation of psychological and pedagogical conditions for the successful development of different types of creative activity that positively affect their socialization. The study uses a set of theoretical and empirical methods of analysis of the studied problem, as well as a comparative study of general and specific features of creativity in children with preserved and impaired hearing. These specific features are determined by a disproportionate formation of different types of thinking, a delay in the development of figurative memory, verbal speech, and imagination in comparison with hearing children. The novelty of the study consists in the expansion of knowledge about the potential possibilities of creative decisions and creative abilities of persons with developmental disorders at different ages in special psychology and pedagogics. The results of the study of creativity of children with hearing impairments can be used in the educational system for professional orientation and creating conditions for persons with special educational needs to master creative professions.
\end{abstract}

Keywords: children with hearing impairments, creative task, education.

\footnotetext{
*Corresponding author: bogdanovatg@mgpu.ru
} 


\section{Introduction}

The study of creativity and creative work of children with disabilities is to some extent a challenge despite the increased tolerance of society and the inclusion of these children and adolescents in the modern educational and socio-cultural space since the level of expectations for the creative achievements of this group of students had been low for a long time.

A small number of works related to different aspects of creativity of disabled children have been published in recent years [1-4]. Creativity is studied in the types of activity that are available depending on the type of disability including visual creativity, theatrical plays, singing, linguistic creativity in the use of gestures, playing musical instruments, composing music, creating literary works of different genres, and sculpture [3, 5-7].

Despite the opinion expressed by L.S. Vygotsky about the creative abilities of children with disabilities, for example, in the practical sphere (as the ability to purposefully use tools), scientists remain cautious when characterizing their creativity [8].

Evidence of such creativity comes from the "creative products" of young and adult people with various disabilities. This is supported by the project "Neprikosaemye" ["Unchurched"] promoting paintings of artists with intellectual disabilities, the project "Naivno? Ochen" ["Naive? Very"], the art studio "Perspektiva" ["Perspective"], the "Teatr Prostodushnykh" ["Theater of the Simple-minded"] where young people with Down syndrome engage in performances, in the "Nedoslov" Theaters of Mimics and Gestures where people with hearing disabilities realize their creative abilities, and in the project "Inklusion" involving deafblind people.

In dyslexia, a specific way of thinking promotes original processing of information, expression of feelings and opinions, and solving everyday problems [9-10].

Individuals with autism spectrum disorders demonstrate a high level of originality in figurative creativity when performing creative tasks [11]. A study of the verbal creativity of individuals with ASD in two aspects, comprehension and production of metaphors, showed that they solve these tasks using a different constellation of cognitive resources $[12,13]$.

A study of the verbal creativity of blind children showed small differences in favor of the visually impaired children. Creativity was particularly high in blind children with high IQ [14].

Special research is needed to create optimal conditions for the realization of creative opportunities for children with developmental disabilities.

The purpose of our study is to explore the creativity of children with disabilities (on the example of hearing-impaired elementary school students).

The study objectives include selecting and testing the method for the assessment of creativity and identifying the general and specific features of the creativity of hearingimpaired children compared to children with normal hearing.

Hypothesis: hearing-impaired children demonstrate less pronounced creativity than their peers with preserved hearing due to a delay in the development of thinking, figurative memory, verbal speech, and imagination.

The novelty of the study is due to the identification of the specific characteristics of creativity in children with hearing impairments that is going to improve the educational practice at the level of general and additional education.

\section{Methods}

A short version of P. Torrance's "Finish Drawing" figure test adapted in Russia is used to study creativity. The tasks are creative and multivariant, do not require special knowledge, and are presented in the form of drawings and their names. The search for a creative solution consists in creating a holistic, objectified drawing from a fragmentary image evoking the 
desire to complete it in the least resource-intensive way which must be counteracted to create a unique product. The instructions for the test sets children up to create unusual drawings. The results are analyzed by several parameters, namely fluency, flexibility, elaborateness, and originality that provide a multidimensional image of the features of creative problemsolving [15].

The study sample includes hearing-impaired children (1st and 4th graders) and children with preserved hearing (2nd graders), 16 per group. The average age of the hearing-impaired 1st graders is 7.9 years and the average age of the hearing 2 nd graders is 7.10 years. The obtained data were compared in two ways: the comparison of creativity indicators in children with preserved versus impaired hearing and the comparison of creativity indicators in hearing-impaired children of different ages.

\section{Results}

A noteworthy observation is a wide variation in the results of children with hearing impairments from good to very low values. A comparison of the quantitative results of the hearing-impaired children and their peers with preserved hearing shows the greatest differences in the indicators of flexibility and elaborateness (Table 1). Differences in fluency are insignificant, however, there is a difference in the approach to performing the task: the hearing-impaired children aspire to complete all figures while their drawings have no meaning behind them - the task is completed but the child cannot explain what they have drawn, they are unable to tell what they depicted or say the first thing that comes to mind. In contrast, the hearing children emphasize the semantic content of the drawing. The hearingimpaired children also use less varied strategies for solving the task and demonstrate rigidity (flexibility 7 compared to 8.6 in children with preserved hearing).

The peculiarities of thinking and less enriched, various, and generalized life experience prevent children with hearing impairments from abstracting and shifting from one test figure to another, therefore, they duplicate the same elements and ideas most often reproducing familiar objects of the surrounding world (different variations of an image of a person is repeated in four cases out of ten).

Table 1. Test results for children with and without hearing impairment.

\begin{tabular}{|l|c|c|c|c|}
\hline Group & Fluency & Flexibility & Originality & Elaborateness \\
\hline Children with imp. hearing & 9.3 & 7 & 9.4 & 16.1 \\
\hline Children with pres. hearing & 9.4 & 8.6 & 11 & 30.8 \\
\hline
\end{tabular}

The greatest differences are found in the elaborateness indicator that demonstrates the ability to elaborate one's ideas (16.1 vs. 30.8). These differences are determined by a wider outlook of hearing children who can embody ideas more completely. Well-drawn fine details and shading are common in their drawings. Drawings of hearing-impaired children are more often schematic and have a minimal amount of details. This feature is determined by the fact that their visual images are less exact and differentiated, as well as less properly preserved in memory [16].

Both groups of children do not demonstrate creativity in naming their drawings, many drawings were left unsigned, although some children had unusual names - "Scent of a Flower", "Book of Wishes", "Volcano on an Island". Children in grades 1-2 did not name their drawings and students with hearing impairments in grade 4 named all of their drawings. 


\section{Discussion}

Numerous observations and few studies of the creativity of children with hearing impairments have linked their problems to communication difficulties that limit the diversity of their experience. The most common characteristic of such children is that they understand everything concretely and literally and have a poor grasp of the meaning of abstract concepts. Some psychologists emphasize that the existing educational system and society do not expect children with hearing impairments to be more creative and, therefore, do not create the conditions for it [17]. Research by foreign psychologists demonstrates trends consistent with our findings: children with hearing impairment are creative when solving creative tasks that do not involve the use of verbal speech [16]. They find unusual and original solutions in different spheres - in visual activities involving the use of images, in solving problems requiring the use of non-verbal means, in the production of gestures [18]. Specific features in the manifestation of creativity of hearing-impaired children are associated with the peculiarities of the cognitive sphere - the delay in the development of perception, memory, thought operations, and combinatorial abilities [19].

Some factors determine creative abilities. The first one is associated with the behavior and level of education of the parents. Hearing mothers of hearing-impaired children are less flexible, more didactic, intrusive, rarely approve of their children's creativity; they are characterized as uncreative which harms their children's creativity. Parents with a high level of education more often demonstrate a creative approach in the upbringing of children and flexibility in the process of communication which has a positive effect on the creativity of their children [20].

The second factor is associated with children's inner resources. The significant restructurization of the processes of actualization of meanings of objects that is achieved through the inclusion of said objects in wide and various semantic connections with other objects and properties of things and the corresponding purpose (to complete a drawing unusually) in its subjective interpretation is evidenced by the increase in the number of ideas and their originality observed in the elementary school age. Motivation comes to the forefront. In solving creative tasks, motives are interconnected with the analysis of task conditions with possible changes that create conditions for the implementation of a creative approach - discovering non-obvious properties of objects and overcoming stereotypes [19]. The activation of personally significant motives creates conditions for setting additional goals, both quantitative - "to finish all figures", and qualitative - "to find interesting solutions". This leads to the intensification of the creative approach manifesting in increased originality and elaborateness of drawings in case of significant motivation [21].

\section{Conclusion}

The improvement of creative abilities in children with disabilities is ensured by work in many areas - the enrichment of life experience, exposure to different types of art by means that account for children's special needs, the development of combinatorial abilities, speech, and thought operations.

For many years, the problem of the development of creativity in children with disabilities had been addressed within the framework of medical treatment and developmental work in the classroom or various academic subjects. The change in the situation is due to a change in priorities: the emphasis is being put on creating and expanding the space of creativity in different areas, schools organize study groups in choreography, music, technology, theater, and sports.

New technologies are being introduced into work with children with disabilities, specifically the methods of art pedagogy in aesthetic education and non-traditional 
techniques (drawing with a candle, poke, landscape monotypes, scribble, etc.) in the fine arts. These methods arouse interest, increase the level of motivation, and contribute to the development of creativity.

Children with disabilities are creative and capable of various creative activities. The suppression of the desire for creativity leads to behavioral problems, conflicts, sometimes to falling out of society. Therefore, parents, teachers, and society as a whole should be aware of the need to create necessary conditions for the implementation of creative abilities of persons with disabilities at all stages of mental development that have certain specifics depending on the particular type of disability.

\section{References}

1. G.A. Stepanova, A.V. Demchuk, Iu.R. Varlakova, Professionalnoe Obrazovanie v Sovremennom Mire [Professional Education in the Modern World], 9(1), 2589-2598 (2019). https://doi.org/10.15372/PEMW20190122

2. L. Heavey, B. Hermelin, L. Crane, L. Pring, Developmental Medicine and Child Neurology, 54, 507-513 (2012). https://doi.org/10.1111/j.1469-8749.2012.04250.x

3. S. Levy, A.J. Robb, D. Jindal-Snape, Disability \& Society, 32(1), 254-268 (2017). https://doi.org/10.1080/09687599.2016.1276433

4. C. Saldaña, International Journal of Special Education, 1(31), 88-96 (2016)

5. Y.P Kuzmenko, A. S Ukolova, Theoretical \& Applied Science, 01(21), 49-54 (2015). https://doi.org/10.15863/TAS.2015.01.21.8

6. B. Junita, M. Sumathi, Education of Disabled Children Music Scholarship, 2, 166-177 (2019). https://doi.org/10.17674/1997-0854.2018.4.166-177

7. O. Hetzroni, H. Agada, M. Leikin, J. Autism. Dev. Disord., 49, 3833-3844 (2019). https://doi.org/10.1007/s10803-019-04094-x

8. L.S. Vygotsky, Metody izucheniia umstvenno otstalogo rebenka. Problemy defektologii [Methods for studying the mentally retarded child. Problems of defectology] (Prosveshchenie, Moscow, 1995)

9. C. Hale, Disability Studies Quarterly, 35(1) (2015). http://dx.doi.org/10.18061/dsq.v35i1.3806

10. A. Cancer, S. Manzoli, A. Antonietti, Cogent Psychology, 3(1), 1190309 (2016). https://doi.org/10.1080/23311908.2016.1190309

11. F.J. Scott, The Development of Imagination in Children with Autism, in M. Taylor (ed.), The Oxford handbook of the development of imagination, 499-516 (Oxford University Press, Oxford, 2013).

https://doi.org/10.1093/oxfordhb/9780195395761.001.0001

12. A. Kasirer, E. Adi-Japha, N. Mashal, Frontiers in Psychology, 11, 1-15 (2020). https://doi.org/10.3389/fpsyg.2020.559238

13. P. Pennisi, L. Giallongo, M Guisi, M.Cannjrozzo, Cognitive Processing, 21(3), 1-36 (2020). https://doi.org/10.1007/s10339-020-00992-6

14. A. Sharmista, Research Journal of Education, 2(4), 64-67 (2016)

15. E. P. Torrance, The Creative Child and Adult Quarterly, 3, 148-158 (1980)

16. M. Marschark, Psychological Development of Deaf Children (Oxford Univ.Press, New York, 1997)

17. D. Daramola, M. B. Bello, A. R. Yusuf, I.Q. O. Amali, International Journal of Instruction, 12(1), 1489-1500 (2019). https://doi.org/10.29333/iji.2019.12195a 
18. C. M. Stanzione, S. M. Perez, A. R. Lederberg, Journal of Deaf Studies and Deaf Education, 18(2), 228-241 (2013). https://doi.org/10.1093/deafed/ens043

19. T.G. Bogdanova, Psikhologicheskii Zhurnal [Psychological Journal], 34(3), 101-109 (2013)

20. A. Lederberg, T. Golbach, Journal of Deaf Studies and Deaf Education, 7(4), 331-345 (2002). https://doi.org/10.1093/deafed/7.4.330

21. T.G. Bogdanova, Kazan Pedagogical Journal, 6(72), 99-106 (2009) 